\title{
USE OF FLAT SLABS IN MULTI-STOREY COMMERCIAL BUILDING
}

\author{
Arti Chandrakant Thakur \\ Department of Civil Engineering \\ SCOE, Kharghar, Maharashtra, India
}

\author{
Roshni John. \\ Department of Civil Engineering \\ SCOE, Kharghar, Maharashtra, India
}

\begin{abstract}
In present era, Flat slab buildings are commonly used for the construction. The use of flat slab building provides many advantages in terms of architectural flexibility, use of space, easier formwork and shorter construction time. The structural efficiency of the flat-slab construction is hindered by its poor performance under earthquake loading. The performance of flat slab and the vulnerability of purely flat slab models under different load conditions and under different grades of concrete were studied and for the analysis, seismic zone III is considered. The analysis is done with using E-Tabs software. It is necessary to analyze seismic behavior of building for different grades of concrete to see what changes are going to occur if the grade flat slab building changes. Therefore, the characteristics of the seismic behavior of flat slab suggest that additional measures for guiding the conception and design of these structures in seismic regions are needed and to improve the performance of building having flat slabs under seismic loading. The object of the present work is to compare the behaviour of multi-storey commercial buildings having different types of flat slabs with different grade of concrete and under seismic forces. Present work provides a good source of information on the parameters lateral displacement, storey drift, storey shear, column moments and axial forces, time period.
\end{abstract}

Keywords - Flat Slab, Types of flat Slab, Grade of Concrete

\section{INTRODUCTION}

Recent market conditions show that the modern infrastructure development is aimed to utilize the available resources to their optimum levels, may the resources be in terms of economy or in terms of space. When the space criterion comes into picture, the utility of maximum space and aesthetics is the main concern of present day architects and designers. The slab that satisfies architectural demand for better illumination, requires simple formwork that can be removed faster (than other slabs) and guarantees open vision while making optimum use of the available space leads to an admired concept in field of structural engineering i.e. reinforced concrete flat slab. Thus flat slabs give an economical alternative in utilizing the internal space to maximum extent. Flat slab is provided in malls, theatres and other structures where large beam free spaces are required.

Study seismic behavior in following types of Flat Slab: -

1. Flat with Drop.

2. Flat slab without drop.

3. Flat slab with drop with opening.

4. Flat slab with drop with opening

Openings in Flat Slab

These flat slabs may have openings for various reasons such as stairways or elevators, electricity, water, the transition of gas and duct for air-conditioning systems, etc. Due to the opening, the discontinuity occurs in load distribution. Which further results in unbalance bending moment and shear force, the punching shear strength also gets considerable affected. Since flat plate slab is already vulnerable to punching shear, opening in such slab may cause great effect on the design parameters of the flat slab. So effects of these openings on the punching shear behavior of flat slab-column systems must be examined carefully due to the vulnerability of such systems to brittle and abrupt punching shear failure.

P-Delta Effect

P-Delta effect, also known as geometric nonlinearity, involves the equilibrium and compatibility relationships of a structural system loaded about its deflected configuration. Of particular concern is the application of gravity load on laterally displaced multi-story building structures. This condition magnifies story drift and certain mechanical behaviors while reducing deformation capacity.

\section{Methodology}

Two methods are used for analyses the flat slab.

- Direct design method

- Equivalent frame method

2.1 Direct Design Method

In the direct design method, the total design moment for a span shall be determine by strip, bounded laterally by the 


\section{International Journal of Engineering Applied Sciences and Technology, 2019 \\ Vol. 4, Issue 3, ISSN No. 2455-2143, Pages 563-568 \\ Published Online July 2019 in IJEAST (http://www.ijeast.com)}

centerline of the panel on each side of the centerline of the supports. The absolute sum of the positive and average negative bending moments in each direction shall be taken as, $\mathrm{M}_{0}=\mathrm{W} / 8$

Where,

$\mathrm{M}_{0}=$ Total moment;

$\mathrm{W}=$ Design load on a total area;

Clear span extending from face to face of columns, capitals, brackets or walls, but not less than $0.65 \mathrm{~L}$

\subsubsection{Distribution of Moment in Flat Slabs}

The equation is how to distribute this total moment to the column and middle strips. If the slab is completely fixed on both the supports than the total moment $\mathrm{M}_{0}$ is distributed as $67 \% \mathrm{M}_{0}$ at support and $33 \% \mathrm{M}_{0}$ at the mid span. The internal spans may be considered as fixed on both the supports.

Accordingly, for internal spans, following values of design moment may be taken as,

Negative design moment $0.65 \mathrm{M} 0$

Positive design moment $0.35 \mathrm{M} 0$

Note, that the negative design moment is located at the face of the supports.

The distribution of total moment in the exterior panel or end span the total design moment $\mathrm{M}_{0}$ shall be distributed as follows. The distribution of total moment in the exterior panel depends on relative stiffness of column and slab meeting at a joint.

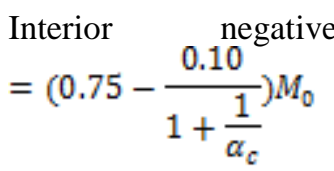

Positive design moment

$$
=\left(0.63-\frac{0.28}{1+\frac{1}{\alpha_{c}}}\right) M_{0}
$$

Exterior negative design moment:

$$
=\left(\frac{0.65}{1+\frac{1}{\alpha_{c}}}\right) M_{0}
$$

To take into account, $\alpha_{C}$ the ratio is define as:

$$
\alpha_{C}=\left(\frac{\sum K_{C}}{K_{S}}\right) M_{0}
$$

Where,

$\alpha_{C}=$ the ratio of flexural stiffness of the exterior column to the flexural stiffness of the slab at a joint. $\sum K_{C}=$ sum of the flexural stiffness of the columns. $K_{5}=$ flexural stiffness of the slab.

Moment in Column Strip:

The column strip moments shall be as follows:

1. Negative moment at an interior support $=75 \%$ of the total negative moment in the panel at that support.

2. Negative moment at an exterior support $=100 \%$ of the total negative moment in the panel at that support.

3. Positive moment for each span $=60 \%$ of the total positive moment in that panel.
Moment in Middle Strip:

The moment to be resisted by middle strip is equal to the moment that is not resisted by column strip.

\section{EXPERIMENT AND RESULT}

1)Modal Time Period

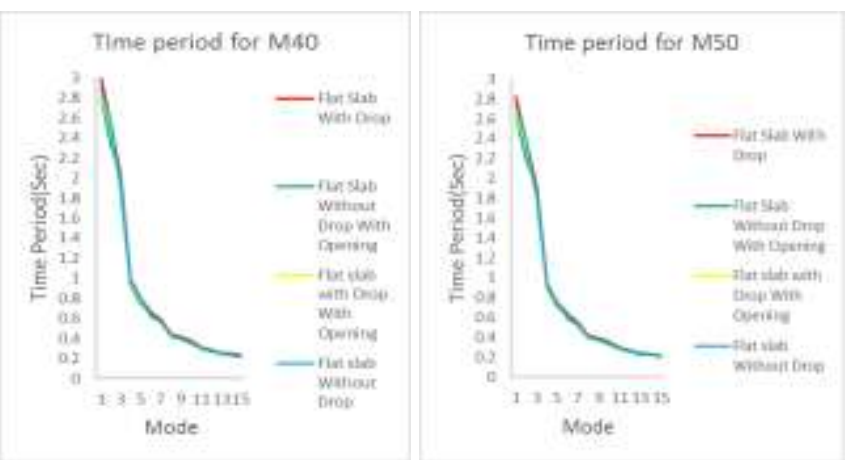

Fig:1.1Modal Time Period M40 Fig:1.2 Modal Time Period M50

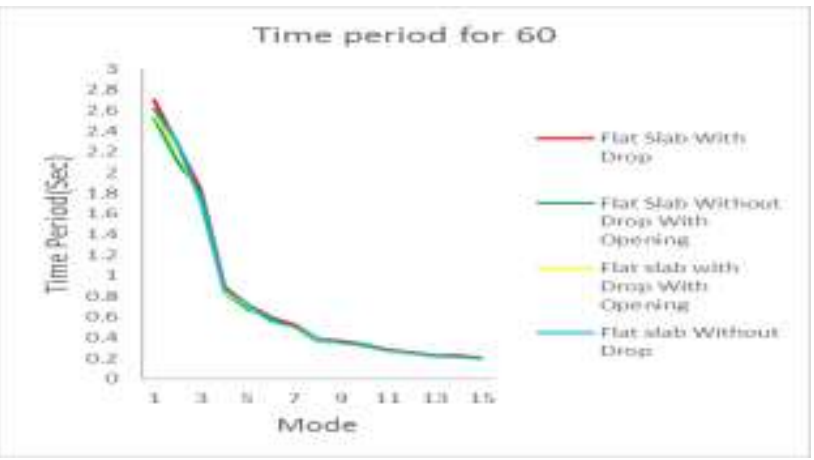

Fig:1.3 Modal Time Period M60

The results have been represented in Fig 1.1-1.3. From the graph it can be observed that the time period is maximum at mode 1 and 2.It is observed that time period is more in flat slab with drop.

2)Lateral Dispacement

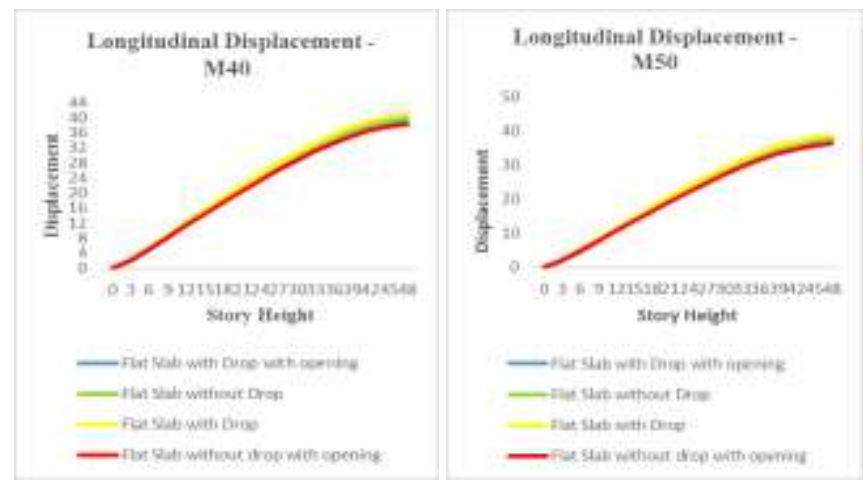

Fig:2.Longi. Displacement M40 Fig2.2 Longi.Dispalement M50 
International Journal of Engineering Applied Sciences and Technology, 2019

Vol. 4, Issue 3, ISSN No. 2455-2143, Pages 563-568

Published Online July 2019 in IJEAST (http://www.ijeast.com)

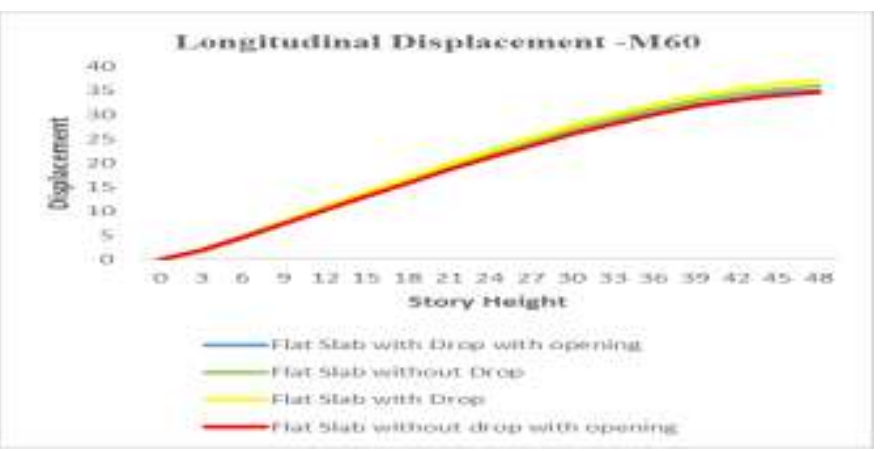

Fig:2.3 Longi.Displacement M60

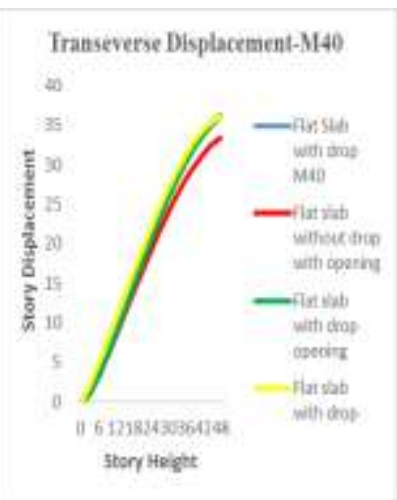

Fig:2.4Trans. Displacement M40

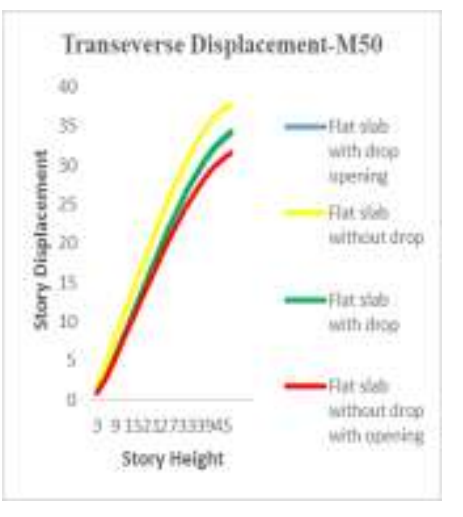

Fig:2.4 Trans.Displacement M40

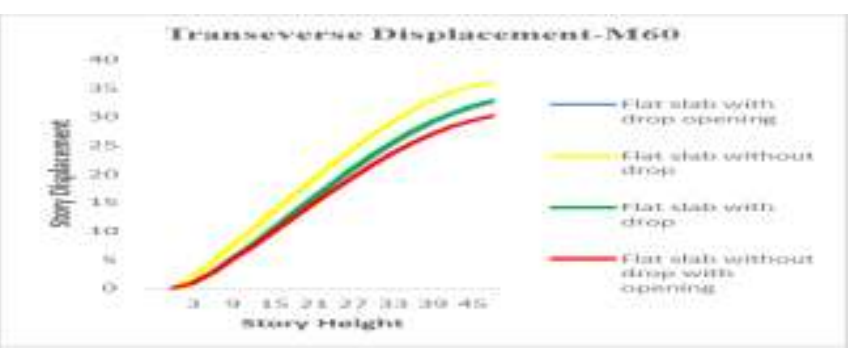

Fig 2.6.Transverse Dispacement

The results have been represented in Fig2.1-2.6. From the Graph it can be observed that the lateral displacement (both $\mathrm{Ux}$ and $\mathrm{Uy}$ ) is maximum at terrace level for all types of column. Lateral displacement increases as the storey level increases. Lateral displacement will be minimum at plinth level and maximum at terrace level.

3)Storey Drift

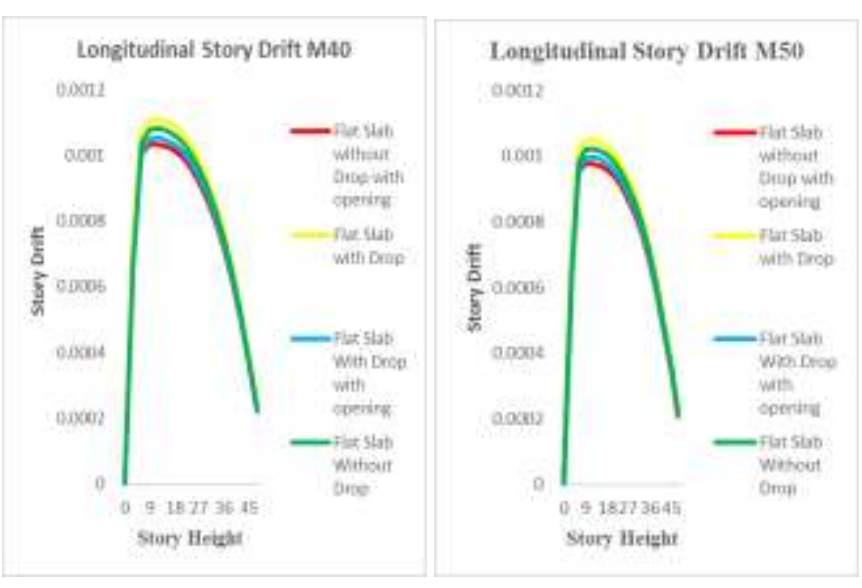

Fig:3.1 Longi.Drift M40

Fig:3.2 Longi Drift M50

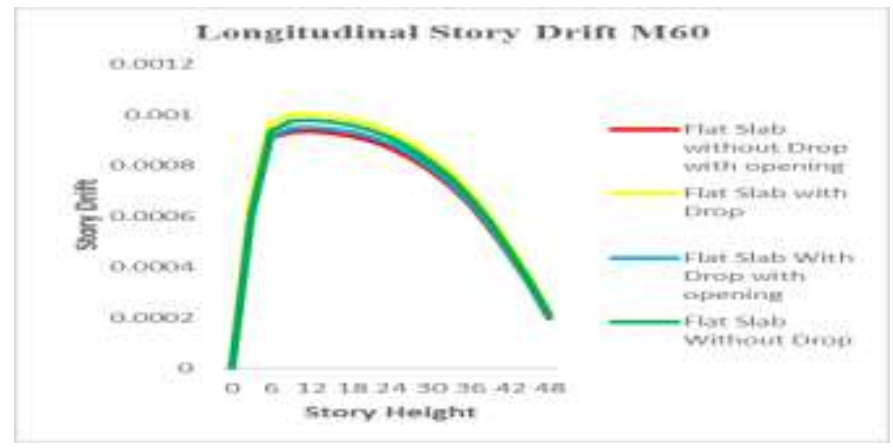

Fig:3.3 Longi.Drift M60

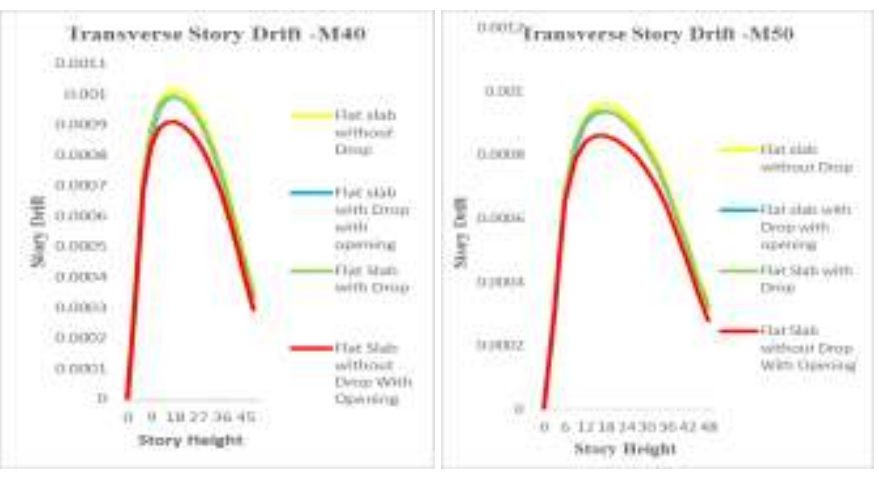

Fig:3.4 Trans.Drift M40

Fig:3.5 Trans.Drift M60 


\section{International Journal of Engineering Applied Sciences and Technology, 2019 \\ Vol. 4, Issue 3, ISSN No. 2455-2143, Pages 563-568 \\ Published Online July 2019 in IJEAST (http://www.ijeast.com)}

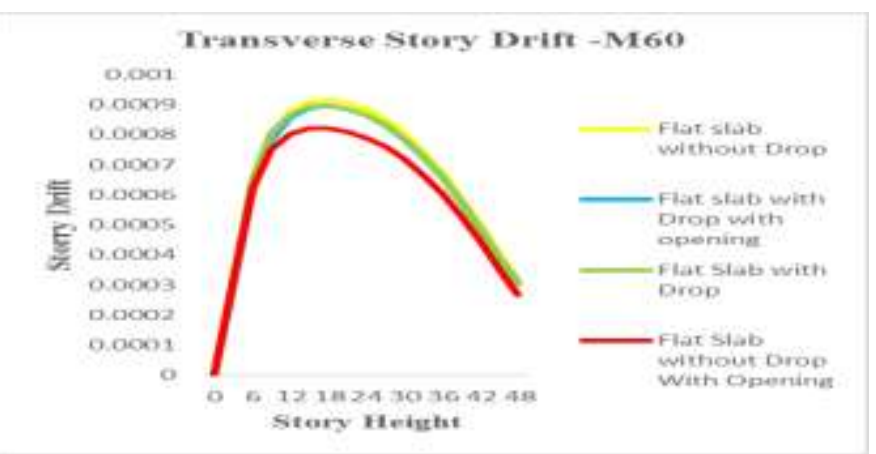

Fig:3.6 Transverse Displacement M60

The results have been represented in Graph 3.1-3.6. From the Graph it can be observed that the storey drift (both Ux and Uy) is maximum at fourth floor for all types of column. After fourth level the storey drift decreases as the height of the building increases.

4)Story Stiffness

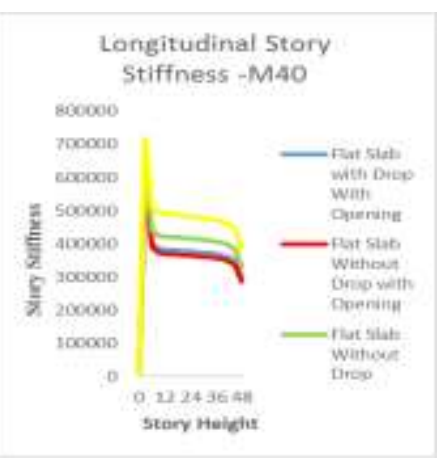

Fig:4.1 Longi. Stiffnss M40

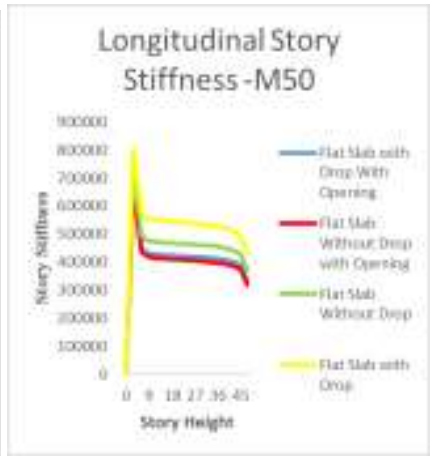

Fig:4.2 Longi.Stiffness M50

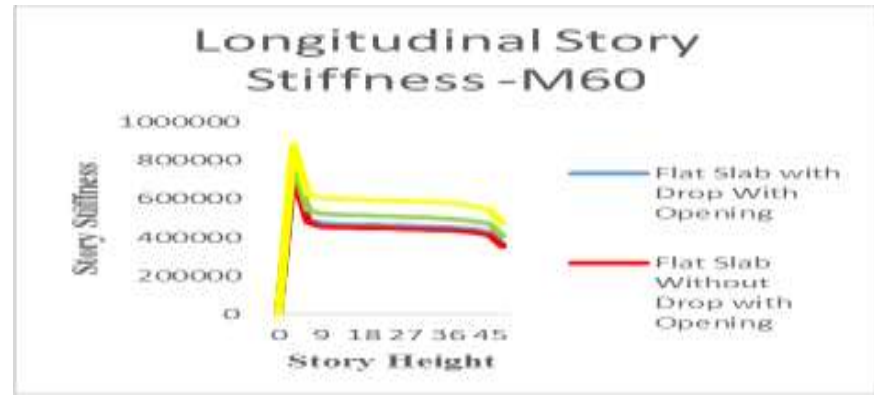

Fig:4.3 Longitudinal stiffness M60

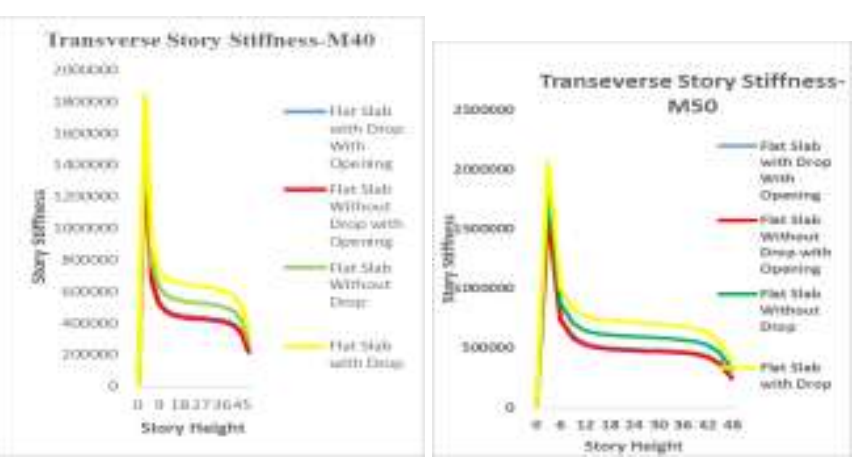

Fig:4.4 Transverse.Stiffness M40

Fig:4.5 Transverse Stiffness M50

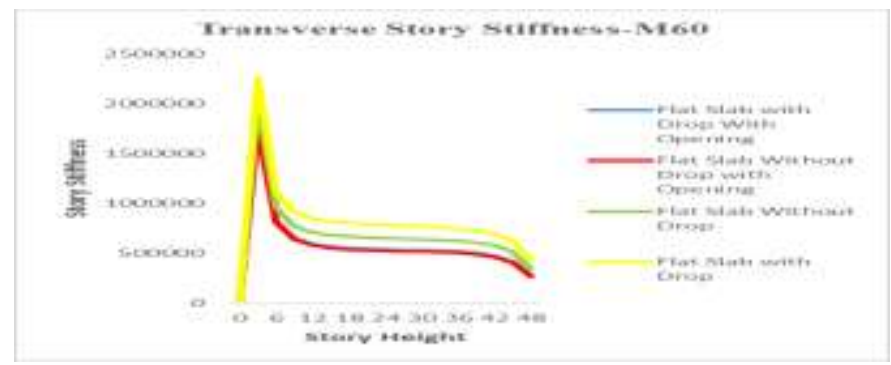

Fig:Transeverse Stiffness M60

The results have been represented in Graph 4.1-4.6. From the Graph it can be observed that the storey stiffness (both Ux and Uy) is maximum at first floor for all types of column.Story Stiffness decreses as height increses.

Base Shear

\begin{tabular}{|c|c|c|c|c|c|c|}
\hline \multicolumn{7}{|c|}{ Base Shear Calculation } \\
\hline Model Name & EQX & EQY & Spec-X & Spec-Y & $\begin{array}{l}\text { Base } \\
\text { Shear } \\
\text { for } \\
\text { EQX }\end{array}$ & $\begin{array}{l}\text { Base } \\
\text { Shear } \\
\text { for } \\
\text { EQY }\end{array}$ \\
\hline $\begin{array}{l}\text { Flat Slab } \\
\text { With Drop }\end{array}$ & 479 & 661 & 359 & 488 & 1336 & 1355 \\
\hline $\begin{array}{l}\text { Flat Slab } \\
\text { Without } \\
\text { Drop }\end{array}$ & 495 & 675 & 371 & 499 & 1334 & 1355 \\
\hline $\begin{array}{ll}\text { Flat Slab } \\
\text { With Drop } \\
\text { With } \\
\text { Opening }\end{array}$ & 444 & 757 & 333 & 561 & 1334 & 1349 \\
\hline $\begin{array}{l}\text { Flat Slab } \\
\text { Without } \\
\text { Drop With } \\
\text { Opening }\end{array}$ & 435 & 730 & 327 & 543 & 1330 & 1345 \\
\hline
\end{tabular}




\section{International Journal of Engineering Applied Sciences and Technology, 2019 Vol. 4, Issue 3, ISSN No. 2455-2143, Pages 563-568 \\ Published Online July 2019 in IJEAST (http://www.ijeast.com)}

From the Chart it can be observed that the base shear is maximum at plinth level for all types of column. After plinth level the base shear decreases as the height of the building increases. Due to the symmetric of the building.

\section{CONCLUSION}

1) The reduction in time period in Flat slab without drop, Flat Slab with Drop with opening and Flat Slab without Drop is $3 \%, 6 \%$ and $7 \%$ as compared with Flat Slab with Drop.

2) Story drift reduced to $2 \%, 6 \%$ and $8 \%$ in Flat slab without drop, Flat slab with drop with opening and flat slab without drop with opening in longer plane and increase in shorter plane with $2 \%, 5 \% .9 \%$ in flat slab with drop with opening, flat slab without drop and Flat slab without drop with opening respectively as compared with flat slab with drop.

3) Story stiffness reduced to $14 \%, 23 \%$ and $26 \%$ in Flat slab without drop, Flat slab with drop with opening and flat slab without drop with opening respectively as compared with flat slab with drop.

4) Lateral Displacement reduced 3\%,6\% and 7\% in Flat Slab without drop, Flat slab with drop with opening and Flat Slab without drop with opening respectively in longer direction as compared with Flat slab with drop in longer direction. Lateral Displacement is minimum at plinth level and maximum at terrace level.

5) Reduction in lateral displacement is negligible in Flat Slab without drop, Flat slab with drop with opening and Flat Slab without drop with opening respectively in shorter direction as compared with Flat slab with drop in shorter direction.

6) Reduction of base shear in Flat slab without drop, Flat slab with drop with opening and flat slab without drop with opening is negligible as compared with Flat slab with drop.

7) Base shear is $20 \%$ more at plinth level for all types of column. After plinth level base shear decrease as height increases. Base shear is more in flat slab with drop as compared with flat slab without drop

8) When we provided opening in flat slab with drop and flat slab without drop performance of flat slab with drop with opening is better than flat slab without drop with opening.

9) Opening in flat slab with drop enhances performance as compared with flat slab without drop.

10) From structural point of view for lateral loading Flat slab with drop is recommended as it increases punching shear resistance and prevent punching shear failure of slabs. A thicker section has better shear stress capacity; the vertical load will be transferred through shear from slab drop to column gradually.

\section{REFERENCE}

1. Christopher H. (1999) "Behavior of composite bridge decks with alternative shear connectors "by ASCE and Heath Mitchell Journal of Bridge Engineering, Vol. 6, Issue01, pp-167-180.

2. Gunup K et.al. (2000), M "Experimental Behavior of Bridge Beams Retrofitted with Post installed Shear Connectors" Journal of Bridge Engineering, Vol.16, Issue 4, pp 19-30

3. Kai Q et.al. (2014) "Dynamic Disproportionate Collapse in Flat-Slab Structures". ASCE, Vol.04, Issue 02, pp 41-55

4. Young S et.al.(2005) "A study of flat plate SlabExperimental and numerical analysis"-, ASCE, Vol.12, Issue 05, pp 273-275.

5. Anis S, Mustapha M et.al.(2016) "Impact of Shear Connector Spacing in Composite Construction Incorporating Cold-Formed Steel Channel Lipped Section" Global Research and Development Journal for Engineering, Vol-1, Issue-6, pp. 6-15.

6. Anuja W, et.al.(2015) "Parametric study of flat slab building with and without shear wall to seismic performance" International Journal of Research in Engineering and Technology, Vol-04, Issue: 05, pp. 82-88.

7. K S Sable et.al.(2012) "Comparative Study of Seismic Behavior of Multistory Flat Slab and Conventional Reinforced Concrete Framed Structures" International Journal of Computer Technology and Electronics Engineering (IJCTEE) Vol- 2, Issue 3, pp 287-300.

8. Mohamed A (2010) "Modeling of Shear-Wall Dominant Symmetrical Flat-Plate Reinforced Concrete Buildings" International Journal of Advanced Structural Engineering. (IJETT), Vol- 10, Issue 12, pp 565-578

9. Martin.O et.al.(2003)" Failure analysis of slabcolumn connections with stud shear Reinforcement, Canadian journal of civil engineering, Vol-08, Issue 05, pp 40-57. 
10. IS 1893 PartI:2002Indian Slandered criteria for earthquake resistant design of structures, Bureau of Indian standards

11. Subramanian N (2014) "evaluation and enhancing the punching shear resistance of flat slabs using HSC" The Indian concrete journal, Vol-06, Issue-02, pp 31-37.

12. IS 456 :2000 Plain and reinforced concrete code of practice, Burro of Indian standards, pp53-61

13. Swamy R et.al.(1982) "Punching shear behavior of reinforced slab-column connections made with steel fiber concrete" ACI Structural Journal. Vol-6, Issue79 pp. 392-406.

14. Theodorakopoulos D et.al.(1993) "Contribution of steel fibers to the strength characteristics of lightweight concrete slab-column connections falling in punching shear" ACI Structural Journal. Vol-04, Issue-90, pp.342-355.

15. Alexander S et.al.(1992)" Punching shear tests of concrete slab-column joints containing fiber reinforcement. ACI Structural Journal. Vol-04, Issue -89, pp. 425-432. (1992). 